\title{
Inclusive Education: Challenges and Prospects in India
}

\author{
*Neetu Antil
}

\begin{abstract}
Inclusive education stands for improvement of schools in all dimensions to address the educational needs of all children. Recommendations to send children with disabilities to mainstream schools were first made in the Sargent Report in 1944, and again in 1964 by the Kothari Commission (Julka, 2005). Despite this, the change has been slow, with segregation in special schools dominating the scene until recently. There is no need of reinforcing the fact that teacher education remains a very weak link with respect to equipping teachers to be prepared for an inclusive classroom environment. The teacher education diplomas and degrees offer "Education of children with special needs" as an optional subject, in order to prepare teachers to identify and diagnose disability. However it gives them a holistic perspective with respect to dealing with diversity or challenge negative attitudes. The challenges and prospects in India are elucidated in the present paper.
\end{abstract}

Keywords: Inclusive education, challenges, prospects, India

\section{Introduction}

Inclusive education means that all children, regardless of their ability level, are included in a mainstream classroom, or in the most appropriate or least restrictive environment (LRE), that students of all ability levels are taught as equals, and that teachers must adjust their curriculum and teaching methodologies so that all students benefit. This also avoids wasting resources, and "shattered hopes," which often occurs in classrooms that are "one size fits all."

There are an estimated 25 million children out of school in India (MHRD 2003 statistics, cited in World Bank, 2004), many of whom are marginalized by factors such as poverty, gender, disability, caste, religion etc. Therefore undoubtedly the idea of inclusive education is certainly highly relevant to our current condition, where differences in religion, faith, gender, ethnicity and ability are often seen as a threat rather than a source of richness and diversity. Inclusive education stands for improvement of schools in all dimensions to address the educational needs of all children. The major support for inclusive education came from the 1994 World conference on Special Needs Education in Salamanca, Spain which emphasized that: Schools should accommodate all children regardless of their physical, intellectual, social, emotional, linguistic or other conditions. The urgency to address the needs of learners who are vulnerable to exclusion through responsive educational opportunities was also highlighted at the Dakar (Senegal) World Education forum in April 2000 where in it was emphasized -"The key challenge is to ensure that the broad vision of education for all as an inclusive concept reflected in national government and funding agency policies. Education for All.... must take account of the needs of the poor and the most disadvantaged, including working children, remote rural dwellers and nomads, and ethnic and linguistic minorities, children, young people and adults affected by conflict, HIV/AIDS, hunger and poor health; and those with special learning needs....".

*M.Sc(Maths),M.Ed,NET(Education),Assistant Professor in Navyug College of Education, Sonipat.

When considering understandings of, approaches to, and impacts of inclusive education, the inevitable diversity and complexity in a context of this size must be taken into account. India's 1.3 billion people speak 18 different languages (GOI, 2002), and 844 dialects (Singal, 2005a), worship varied religions, have unique customs, differ in their exposure to disease and access to types of nutrition which affect their health and socio economic status, and also communication which influence their access to government resources such as education or healthcare.

This diversity is further reflected in disparities of educational achievement. For example in Kerala the literacy rate recorded in the 2001 census was $90.92 \%$, while in Bihar it was $47.53 \%$ (GOI, 2002). As a result, the overall (average) literacy rate for India was $65.38 \%$ which, while a representative figure cannot reflect the complexity of context (Govinda and Biswal, 2006). Added to this issue of averaging out statistics in such a vast country is the fact that when census data was collected there were some areas which were cut off by "disturbances" or "natural calamities" (GOI, 2002:11) such as the Kashmir conflict, floods or landslides. Data on children with disabilities seems to be unreliable, perhaps due to Filmer's (2005:3) "selective reporting" of obvious physical impairments, or children being hidden by their families out of shame. A basic disability statistic was recently included in the 2001 Census for the first time, as a result of campaigning by the Indian 
disability movement (Thomas, 2005). Despite there being no disability indicators in the influential EFA Global monitoring reports, the addition of the disability statistic may indicate the positive influence of the introduction of the inclusive education concept. In India disability is measured in five categories - sight, speech, hearing, locomotors and mental which excludes disabilities such as autism. It is worth noting that according to the 2002 National Sample Survey, only $45 \%$ of the disabled population is literate, and $9 \%$ has secondary level education or higher (Thomas, 2005).

While impairment is not restricted to any one class or age group, people with disabilities are often found to be amongst the poorest of the poor (Hans, 2003; DFID, 2000) However, a caste/disability link does not seem to have been empirically researched to date in the Indian context. There are many govt. and NGO programmes focused on caste and gender in India, yet none seem to be concerned with how disability interacts and reinforces these dimensions of exclusion. For example, the multiple handicap of being a disabled woman can manifest itself in many ways. Her marriage chances are slight (Coleridge, 1993) she may be more subject to infanticide, her dowry higher as she is perceived as infertile, she is more likely to be abused or hidden from public view by her family, and she ".... ceases to exist as a person and is excluded from being recognized as a woman in the fullest sense because she does not fit in with the model of women defined by society and dear to the collective imagination." (Hans, 2003:22). Although the govt. of India over the years initiated and implemented a number of programmes such as Integrated Education for Disabled Children (IEDC), Project on Integrated Education for Disabled (PIED) funded by UNICEF and govt. by NCERT, DPEP, Janshala, SSA etc which have led to increase in enrolment and retention but only a miniscule of children with disabilities have been integrated in mainstream institutions. It is estimated that around 1000 NGOs and voluntary organizations are actively engaged in education (GOI, 2000). One noted example is the Spastics Society of India (SSI). They are working for all children marginalized from learning, including girls and working children, operating inclusive preschool classrooms in Mumbai's slum areas. In addition, they offer a post graduate diploma in inclusive education among other courses, in order to clarify this much misunderstood concept.

\section{Inclusive Education Policy}

Recommendations to send children with disabilities to mainstream schools were first made in the Sargent Report in 1944, and again in 1964 by the Kothari Commission (Julka, 2005). Despite this, the change has been slow, with segregation in special schools dominating the scene until recently. The 1995 Persons with Disability Act (PDA) states that disabled children should be educated in integrated settings where possible, although it seems that the lack of implementation may be due to there being no enforcement agency for this legislation. Despite the promotion of inclusive education, govt. documents focus on inclusive education as being about including children with disabilities in the education system, but not specifically the mainstream (Singal, 2005a). However, inclusion in the education system is not the same as inclusion in the mainstream. It is however arguable that special education is in fact regarded as superior in India due to its preferred status (Mukhopadhyay and Mani, 2002) and that it is inclusion in the mainstream that is currently seen as the resource - constrained inferior alternative. However the limited coverage of mainly urban-based, impairment specific special schools in India may resultin the exclusion of children with disabilities who do not fit the categories of their institutions or who live in rural areas. Inclusive education may be the only way of facilitating educational access for these children. A focus on physical access to school, rather than access to curriculum and equal treatment once in the classroom (Thomas, 2005) is an additional barrier to inclusion, possibly resulting in dropout. Singal (2005a) too argues that government policy focus on resources and physical access (e.g. distribution of aids and appliances), or infrastructure such as ramps in schools, and the notion of social justice through equal distribution of benefit, seems to be more about inputs, not processes like pedagogy, curriculum or attitudes. It is this focus which results in selection of the relatively few-"Easy to accommodate children" with mild or moderate disabilities that do not need too much specialist assistance. This apparently selective inclusion, with children being 'prepared' in order to be 'ready' for the mainstream (NIEPA, 2003) seems to give inclusive education an exclusive flavor, although this may be because homogeneity in the classroom can be perceived as an essential prerequisite to enable good teaching (Singal, 2005). This appears to directly contradict the understanding of inclusive education as a concept which is all about embracing diversity in the classroom. Despite islands of govt. programme success, disability budgets remain under used (Thomas, 2005), and reserved jobs unfilled (Bhan 2006; Thomas, 2005). These are sure signs of sporadic implementation of inclusive education, as is the persistently low percentage of children with disabilities being in school.

\section{Teacher Education Programmes}

There is no need of reinforcing the fact that teacher education remains a very weak link with respect to equipping teachers to be prepared for an inclusive classroom environment. The teacher education diplomas and degrees offer "Education of children with special needs" as an optional subject, in order to prepare teachers to identify and diagnose disability. However it gives them a holistic perspective with respect to dealing with 
diversity or challenge negative attitudes. This reinforces the 'difference' of children with disabilities who, some believe, can only be taught by teachers qualified specifically for them (Signal, 2005a). Although, it is ultimately teacher treatment of students in the classroom, rather than the training per se, that would reinforce this difference. Interestingly, distrust in both the special and mainstream education systems leads some parents to keep children with disabilities at home for fear of their abuse or neglect in the classroom (Julka, 2005); which may then be interpreted by teachers as a lack of community interest in education for their children, as demonstrated in the PROBE Report (PROBE,1999). There is evidence to suggest that many teachers do not feel equipped to teach children with disabilities and complain that they need more time to instruct these students (Mukhopadhay, nd). Many government programmes have included a teacher training component in an attempt to instigate institutional change. However, a 'special needs' focus and a lack of training for management, combined with didactic training methodology do little to alter the classroom. The poor quality educational provision in many schools is reflected in the fact that many govt. job reservations for adults with disabilities remain unfilled. It is more likely to be directly related to the fact that very few children with disabilities get to, or stay in, school that there is a lack qualified, let alone confident candidates.

\section{Infrastructural support}

A small pool of resources (41\% of GDP for education UNDP, 2005:256) despite a promised $6 \%$ by 2000 (GOI, 2002) combined with high demand, suggests that the development of the mainstream would be a more financially effective and efficient way to go (Peters, 2004; UNESCO, 2003). This could result in smaller classes and better teaching which would benefit all students (Singal, 2005). Arguably, resources would not be so limited after all if all specialist institutions were moved to the mainstream, which may explain why Thomas (2005) argues that, there are indeed sufficient resources in India to implement inclusive education. However, this solution could mean that the essential services which some special schools provide (and would still be needed) would be spread wider, and thinner. Although external donor support can be perceived as insignificant in the context of the Central government overall education budget (Thomas, 2005b), there appears to be extensive external funding of programmes aiming to improve accessibility of mainstream schools to marginalized children, including those with disabilities. While external assistance can help the government to tackle its resources 'crunch' in the short term, it may also be having a negative effect on the political will needed to make a $6 \%$ GDP allocation to education. This lack of political will further reflected in the seemingly continuous string of externally assisted government education programmes that fall short of their goals. With no consequences of an accountability mechanism in sight, they are simply left to wither and die while everyone moves on to the next programme with all the mnew funding and revised goals.

\section{Prospects of Inclusive Education}

Inclusive education is a developmental approach seeking to address the learning needs of all children, youth and adults with a specific focus on those who are vulnerable to marginalization and exclusion. An increasing number of publications, policy papers, workshops etc. have supported the ideology of inclusion. Some organizations and people, however, doubt whether the ordinary classroom can provide quality education for disabled children. This debate has been on, ever since people began to voice their reservation against old segregated institutions and in turn raised their concern for equality of disabled children. These concerns must be taken seriously and dispelled by showing examples of positive experiences, which clearly demonstrate that inclusive education most definitely addresses quality issues in education. The major goal of inclusive education is the Flagship goal. Recognizing the right to education, the Flagship seeks to unite all EFA partners in their efforts to provide access to quality education for every child, youth and adult with a disability. The Flagship has been formed by an alliance of diverse organizations, including global disability organizations, international developmental agencies, intergovernmental agencies, and experts in the field of special and inclusive education. In order to reach this goal, the flagship will: - Have the full participation of persons with disabilities and families in the design of all Flagship activities.Promote the full participation of persons with disabilities and families in the development of policies and guidelines related to the education of persons with disabilities at local, national, regional and global levels. Seek to ensure that all governmental entities, donors and NGOs endorse the universal right to education for all children, youth and adults with a disability. A Act as a catalyst to fully incorporate the Flagship goal into national plans of action and regional policies. Seek to ensure that the EFA monitoring process includes specific quantitative and qualitative statistics and indicators related to persons with disabilities and documentation of resources allocated to the implementation of EFA for these individuals. - Identify and disseminate effective practices and stimulate research and studies related to the Flagship goal to include such areas as:

Quality teacher education

Curriculum and pedagogy

School organization including adequate accessible facilities 
Aids and appropriate materials

Many countries have developed programs, which promote equality of opportunity by allocating specific funds to areas of social and economic need. If inclusion is to be successful, the following parameters need to be taken care of:

* Encouragement provided by the community for including children with disabilities in local schools.

* Readiness of the general education system to accept responsibility for education of children with disabilities.

*Willingness of parents of children with disabilities to send their wards to local schools.

* General classroom teachers to be equipped to manage the education of children with disabilities.

*Enrolment rate of children with disabilities at least on par with that of nondisabled children.

*Retention of children with disabilities in schools.

Availability of support from peer group to children with disabilities and vice-versa in teaching learning processes.

* Comparable achievement of children with disabilities in curricular and cocurricular activities at par with their capabilities.

* Availability of specialist teacher support, if possible to the regular classroom teachers.

Thus, we as teachers, parents, teacher-educators etc have to facilitate the implementation of inclusive education not only as a program but also as an ideology- an ideology based on the principles of human rights approach wherein stress is laid on giving importance to the individual and respecting his/her potentiality in the teachinglearning process.

\section{Conclusion}

It is important to remember that Inclusive education is at a very early stage of conceptualization and implementation in India. The fact that it is being discussed, debated and in some places implemented although falteringly, demonstrates a willingness to engage with elements with elements of a new concept that has the potential to be developed in the future in a positive manner. So long as the "struggle to achieve compulsory education for a majority of children takes precedence over meeting the needs of those with disabilities..." (Ainscow etal, 1995 cited in Singal, 2005b:338), change for children with disabilities will continue to be sporadic and painfully slow. The division of educational responsibly for children, between the MSJE for those with disabilities and the MHRD for those with disabilities and the MHRD for those without, can only exacerbate this struggle, and highlight the 'different' nature of children with disabilities needs and the special needs focus of inclusive education with it. This implies that if inclusive education came under one ministry, most probably the MHRD, potentially both conceptualization and implementation could be clarified and promoted, while the needs of children with disabilities could finally be mainstreamed. The absence of accountability mechanisms, which results in poor policy implementation, suggests that in order to ensure implementation of 1995's Persons with Disabilities Act, some kind of legal enforcement mechanism needs to be created (Alur, 2002), perhaps related to resources allocation or government employee contract renewal. The absence of reliable assessment and strong enforcement mechanisms is perhaps one of the reasons why so many govt. programmes whether away, targets unfulfilled, and govt. departments remain unchanged despite repeated failure. Human resources potential aside, without education, marginalized children may not be able to fulfill their rights as citizens (Tomasevski, 2003) in the largest democracy of the world. Inclusive education thus needs to be implemented with full rigour in order to fulfill the mandate of Education for all as guaranteed by the Fundamental Right to education declared by the 86th Constitutional amendment act in 2002 and enacted as a law in the year 2009 .

\section{References}

[1]. Ainscow, M. (2005) From Special Education to Effective Schools for All, Keynote presentation at the Inclusive and Supportive Education Congress 2005, University of Strathclyde, Glasgow

[2]. Alur, M. (2002) Introduction, in Hegarty, S \& Alur M (eds) (2002) Education and Children with Special Needs: from Segregation to Inclusion, New Delhi: Sage Publications

[3]. Balagopalan, S. \& Subrahmanian, R. (2003) Dalit and Adivasi Children in Schools: Some preliminary Research Themes and Findings, in IDS Bulletin, 34 (1), 2003, Falmer: Institute of Development Studies

[4]. Bhambani, M. (2003) Societal Responses to women with Disabilities in India, in Hans, A \& Patri, A (eds) (2003) Women, Disability and Identity, New Delhi: Sage Publications

[5]. Bhan, S. (2006) Arm Them with Land, in India Today International, May 2006,p.18 Booth, T., Nes, K., \& Stromstad, M. (eds) (2003) Developing Inclusive Teacher Education, London: Routlege Falmer

[6]. Clough, P., \& Corbett, J. (2000), Theories of Inclusive Esucation, London: Paul Chapman Publishing, Sage

[7]. Constitution of India (1949) Constitution of India, Article 41, New Delhi: Ministry of Law and Justice, accessed at: http://indiacode.nic.in/coiweb/fullactl.asp?tfnm $=00 \% 2052$

[8]. Dasgupta, P. R. (2002) Education for the Disabled, in Hegarty, S. \& Alur M. (eds) (2002) Education and Children with Special Needs: From Sedregation to Inclusion, New Delhi: Sage Publications

[9]. De Haan, A (1998) 'Social Exclusion': An Alternative Concept for the Study of Deprivation? IDS Bulletin, Vol. 29 (1), 1998, Falmer: Institute of Development Studies .

[10]. Discrimination based on caste, religion, disability-Handbook sensitizing teachers and teacher educators (Inclusive Education)published by NCTE 2004 under the agencies of Human Rights Commission. 
[11]. DFID (2001) Children Out of School, London: Department for International Development

[12]. GOI (2000) India: Education For All Year 2000 Assessment, Ministry of Human Resources Development, New Delhi: Government of India

[13]. GOI (2002) India 2002: A Reference Annual, Publications Divison, Ministry of Information and Broadcasting, New Delhi: Government of India

[14]. GOI (2003) Annual Report 2002-2003, Department of Elementary Education and Literacy, Department of Secondary Education and Higher Education, Ministry of Human Resource Development, New Delhi: Government of India

[15]. Govinda, R. and Biswal, K. (2006) Access to elementary Education in India: Identifying Consortium for Research on Education, in Hans, A \& Patri, A (eds) (2003) Women, Disability and Identity, New Delhi: Sage Publications Hans, A. \& Patri, A. (eds) (2003) Women, Sisability and Identity, New Delhi: Sage Publications

[16]. Holdsworth, J. (1994) China, Integrated Education Project, Anhui Province, in Making it happen: Examples of good practice in special Needs Education and Community http:// unesdoc.unesco.org/images/0009/000968/096884ev.pdf

[17]. Jangira, N. K.(2002) Special Education Needs of Children and Young Adults: An Unfinished Agenda, in Hegarty, S \& Alur M (eds) (2002) Education and Children with Special Needs: from Segregation to Inclusion, New Delhi: Sage Publication.

[18]. Jha M. M. (2002) School Without Walls: Inclusive Education for All Oxford: Heinemann

[19]. Miles, S. (2000) Enabling Inclusive Education: Challenges \& Dilemmas, paper presented at aSymposium on Development Policy entitled "Children with Disabilities and the Convention on the rights of the child" Gustav Stresemann Institute, Bonn, Germany, October 27-29, 2000, accessed at: http://www.eenet.oprg.uk/theory_practice/bonn_2.shtml

[20]. Ministry of Human Resource Development (MHRD) (2006), Inclusive Education- Draft Action Plan for Inclusive Education of Children and Youth with Disabilities, New Delhi: MHIRD, accessed at : www.eduatio.nic.in/htmlweb/inclusiveeducationactlonplan.htm

[21]. Mukhopadhyay, S. (2003) (ed) National Seminar on Partnership of Government and Nongovernment Organization for Inclusive Education (October 15-17,2003) Report, New Delhi: National Institute of Educational Planning and Administration

[22]. Mukhopadhyay, S. \& Mani, M. N. G. (2002) Education of Children with Special Needs, in Govinda, R. (2002) (ed) India Education Report, Niepa, New Delhi: Oxford University Press (pp.96-108).

[23]. PROBE Team (1999) Public Report on Basic Education in India, New Delhi: Oxford University Press.

[24]. Singal, N. (2005a) Responding to difference: Policies 'inclusive education' in India, paper presented at the Inclusive and Supportive Education Congress 2005, University of Strathclyde, Glasgow.

[25]. Thomas, P. (2004) DFID and Disability: A Mapping of the Department for International Development and Disability Issues, London: Disability Knowledge and Research, accessed at: http://www.dfid.gov.uk/pubs/files/disability/dfid-and-disability.pdf

[26]. Thomas, P. (2005a) Disability, Poverty and the Millennium Development Goals: Relevance, accessed at:http://disabilitykar.net/research/pol final:html

[27]. Tomasevski, K. (2003) Education Denied: Costs \& Remedies, London: Zed Books.

[28]. Tomlinson, S. (1982) ' Theoretical influences on the establishment of inclusive practices' in Cambridge Journal of Education, Vol. 26, No. 1

[29]. [UNESCO (1994). The Salamanca Statement and Framework on Special Needs Education. Paris: UNESCO 